\title{
Improving Adaptive Learning in a Smart Learning Environment
}

\author{
Gilberto Marzano \\ Rezekne Academy of Technolologies \\ Rezekne, Latvia \\ gilberto.marzano@rta.lv
}

\author{
Anda Abuze \\ Rezekne Academy of Technologies \\ Rezekne, Latvia \\ anda.abuze@rta.lv
}

\author{
Yeliz Nur Akarcay \\ Saricam Public Education Center \\ Adana, Turkey \\ yeliznur@gmail.com
}

\begin{abstract}
It has been broadly argued that, in the near future, the demand for skilled labor will increase whilst that for routine activities will decrease. In this regard, the need for making greater investments in education to re-skill workers and support continuous learning has been invoked as an essential requirement for preserving people's employability.

Digital technology is deemed increasingly necessary to sustain the educational endeavor, for the possibilities it offers to make more accessible and low-cost educational interventions. It allows for the creation of personalized learning paths and customized digital learning solutions, for courses to be available to a large attendance of learners, and for teaching-learning activities to be offered at significantly reduced cost.
\end{abstract}

In this article, a learning unit structure designed to improve adaptive learning is proposed, and mechanisms for adaptive learning in a smart learning environment are discussed.

The implemented teaching-learning solution is also illustrated. This is a preliminary application based on an approach that combines the teacher experience with learning analytics.

Keywords - Learning Adaptivity, Learning Analytics, Learning Unit Structure, Smart Learning Environment.

\section{INTRODUCTION}

Nowadays, an increasing amount of research in the educational scope focuses on technology that can be used to increase teaching-learning productivity and efficiency.

In 2020, the COVID-19 pandemic severely impacted on educational systems worldwide, forcing a transition from face-to-face teaching to remote teaching-learning and elearning. Data from surveys conducted during the resulting shut down of educational institutions reveals a broad consensus regarding the positive attributes of the so-called emergency remote teaching, even if the organization of remote classes, virtual exams, and the various bureaucratic activities proved extremely challenging at the time [1], [2], [3], [4], [5]. The massive and unprecedented use of technology in training activities as a result of the outbreak made the question of how to enhance personalized learning experiences in a digital environment more topical.

Creating personalized learning paths and customizing digital learning can allow educators to reach very large audiences of learners, whilst also reducing the cost of teaching-learning activities.

Oppermann and Rasher distinguished between learning adaptivity and learning adaptability [6] referring to adaptivity to a system that adapts itself according to the user rather than forcing the users to change its behavior (adaptability). According to the authors, in learning systems, the application of adaptivity finds more suitability than adaptability. Currently, many adaptive learning platforms are available that promise the application of adaptive learning for personalizing the learning process, whilst numerous investigations are being carried out on the use of adaptive learning in various scopes [7], [8].

Adaptive learning solutions are often based on learning analytics [9]. The last few years have seen an increased interest in learning analytics and adaptive learning, since online and mobile technologies have facilitated access to a huge wealth of data that can be used to customize the learning process. The use of analytics in education can enhance many aspects of the teaching-learning experience. Data produced by students during training activities can be used to improve their achievements and proficiency.

The personalization of learning content and modality is crucial for disadvantaged groups since, usually, teachers aim their activities to match the needs of the average student whilst, in reality, a great number of students do not correspond to this profile. Furthermore, learning analytics can improve remote teaching-learning, helping teachers to 
identify learners who are insufficiently challenged, bored, confused, or who are failing to attend [10].

This paper presents an application based on SALM (Smart Adaptive Learning Model) that results from research carried out within the scope of two international projects, DocTDLL (Implementation of Transformative Digital Learning in Doctoral Program of Pedagogical Science in Latvia), whose aim is the application of Transformative Digital Learning to Ph.D. study programs, and ASL (Adult self-learning: supporting learning autonomy in a technology-mediated environment), which is aimed at improving and extending the supply of highquality learning opportunities tailored to the needs of individual low-skilled or low-qualified adults.

\section{RESEARCH OBJECTIVE AND METHODOLOGY}

The main research objective lay in defining and implementing a smart learning environment able to support adaptive learning processes. According to Huang, Yang, \& $\mathrm{Hu}$ (2012) [11], a smart learning environment is based on technical components that provide learners with appropriate support (such as guidance, feedback, hints, or tools) in the right place and at the right time. It should meet individual learners' characteristics and needs, which might be determined by analyzing their learning behavior, performance, and the online and real-world contexts in which they are situated.

This research foresees three phases:

1. Analysis of experience in adaptive learning and learning analytics in order to define the smart learning environment's functional structure.

2. Implementation of a preliminary solution based on structured learning units and the automatic creation of personalized learning paths combining teacher expertise and learner behavior.

3. Integration of e-learning and remote learning with virtual agents, and creation of learner profiles based on a weighted analysis of their preferences and achievements.

The methodology adopted was to analyze experiences gathered in structuring learning units and the SCORM (Shareable Content Object Reference Model) [12]. Although SCORM presents limitations in ensuring security, sequencing, and interoperability in the learning content [13], it is a conceptual reference model in the creation of learning objects.

At this time, phase 1 and phase 2 have both been concluded.

A smart learning environment has been defined that integrates solutions for context-sensitive and customized learning in order to accelerate and enhance learner proficiency. Following this, an experimental application has been implemented to provide learners with individual learning paths automatically, based on their own knowledge level and supported with specific options at different learning stages, e.g. providing low-qualified learners with additional didactic materials to fill their knowledge gaps.

\section{SALM FUNCTIONAL STRUCTURE}

SALM is inspired by the principles of adaptive learning [14], namely the delivery of custom training through justin-time feedback, pathways, and resources.

Fig. 1 shows the functional structure of SALM [15].

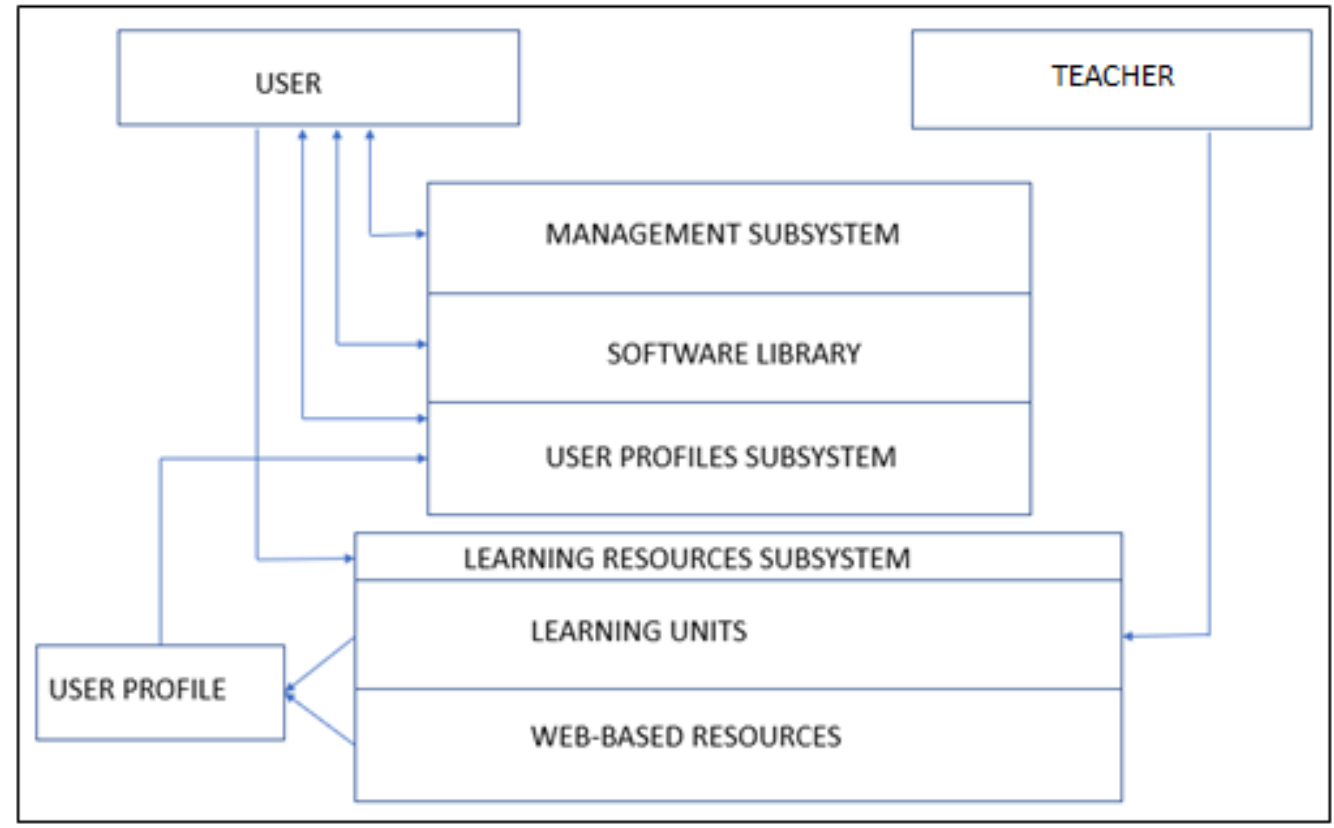

Fig. 1. SALM functional structure (own source) 
The main components of SALM are:

1. Management subsystem that encompasses functions to support:

0 interaction between learners and teachers;

o interaction among learners;

o building of user profiles;

o building of learning units;

o organization of customized learning path;

o filtering of resources according to learner profiles;

o evaluation of learning retention;

o analysis of learning resources to create ontologies.

2. Software library, which includes programs and algorithms to:

o perform intelligent searches on the web according to learner profiles;

o make inferences to select learning resources according to user profiles;

o calculate the learning rate;

o evaluate the learner status.

3. Profile subsystem, which contains the profiles of users, recorded as the result of an analysis of their activity.

4. Resources subsystem, which is divided into integrative learning materials and web-based learning resources. The former includes lectures and didactic materials such as course notes, slideware, study guides, self-assessment questionnaires, etc. The latter includes web searches, such as links to didactic objects, websites, articles, audio/video objects, etc.

Trainers prepare learning units, but learners have the possibility to add new learning resources gathered from their own activity on the web. These resources are listed under the see also section of a learning unit.

In the SALM model, the structure of learning units plays a crucial role, since a significant degree of adaptive learning performance depends on how learning units have been created [16].

\section{SALM STRUCTURED LEARNING UNITS}

Learning units are objects comprising various multimedia components (Fig. 2):

- Learning objects;

- Questions;

- Chat;

- Forum;

- Integrative materials;

- $\quad$ Final test. data:

Each learning unit contains a header with the following

- $\quad$ Name of the author (s);

- Organization (name of the author's organization);

- Date of creation (derived automatically);

- $\quad$ Date of the last update (derived automatically);

- Title;

- Summary;

- Keywords;

- $\quad$ Expected achievement;

- $\quad$ Prerequisites (knowledge that a learner should possess).

Learning objects are the basic learning items/resources of a learning unit, and can be figured as the bricks in a Lego construction.

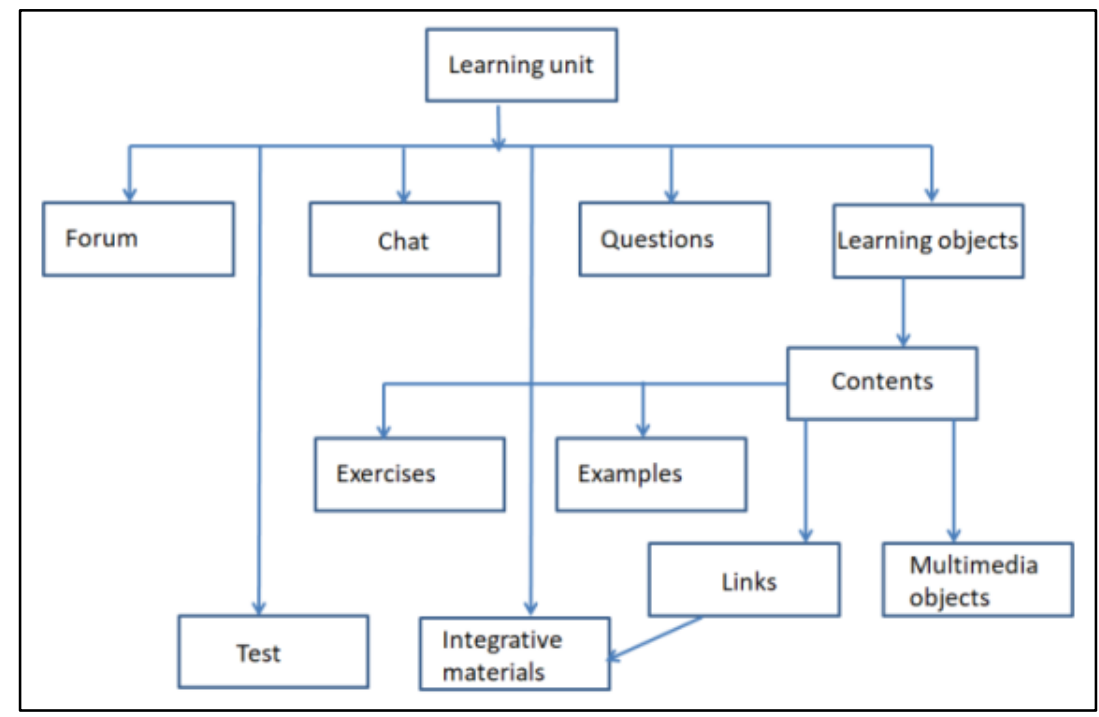

Fig. 2. A learning unit structure (own source) 
Learning objects have been described in literature in many different ways, depending on the background of the author and their application context [17]. They are addressed variously as learning objects, information objects, instructional objects, educational objects, content objects, media objects, knowledge objects, and so on. However they are defined, the key element that is emphasized is their reusability:

- A digital resource that can be reused to support learning [18].

- Any entity, digital or non-digital, that may be used for learning, education, or training [19].

- A small piece of learning material (e.g. visualization, video clip, animation, interactive simulation, interactive exercises) that is a reusable, compact, and unitary entity [20].

In SALM learning objects are:

1. Contents (multimedia objects and links)

2. Examples

3. Exercises

Contents can include:

- links to integrative materials, namely learning objects that a teacher creates for or associates to a learning unit;

- embedded multimedia objects, such as video, schemes, pools, etc.

Integrative learning materials play a crucial role in the SALM adaptive teaching-learning solution. They correspond to the learning materials that the teacher didn't include in a learning unit but deem essential to understanding it. Usually, these materials refer to definitions, general principles, theories, etc., that a skilled learner should know or should be able to find by consulting a dictionary, an encyclopedia, or the web.

Integrative learning materials include:

- $\quad$ pre-knowledge needed for the learning unit contents;

- supplementary readings, examples, and exercises.

Due to its nature, the same integrative material can be associated to more than one learning unit.

\section{THE TEACHING LEARNING SOLUTION}

A pre-determined but flexible teaching strategy has been adopted. The teacher defines the initial decision tree that can then be dynamically changed leveraging the individual student data.

A two-step teaching-learning solution has been implemented to support learners who might have difficulty accessing these notions and/or selecting the right source. The first step consists in the creation of the initial set of integrative materials. The teacher defines and prepares the materials that should be part of a learning unit. These can be accessed through links that are included in learning object content in the event that a learner has difficulty understanding something. First, the teacher defines some questions for testing the level of knowledge of a learner. Then, based on the learner responses, the learning unit is generated, assembling the learning objects and adding the integrative materials, corresponding to the knowledge gaps identified through the teacher questions.

Examples of initial questions for a learning unit concerning "Internet searching” might be:

- Do you know the difference between an internet browser and an internet search engine?

- Do you know the difference between e-marketing and e-commerce?

- Do you know the history of the internet?

- Do you know the basic functioning of a computer?

- Do you know something more about information retrieval?

The teacher can create integrative materials, such as:

- Browser definition

- Most popular browsers

- $\quad$ Search engine definition

- Bio of Tim Berners-Lee

- WWW definition

- What a network is

- History of the internet

- ...

Fig. 3 shows the integrative materials associated with the question "Do you know the difference between an internet browser and an internet search engine?” 


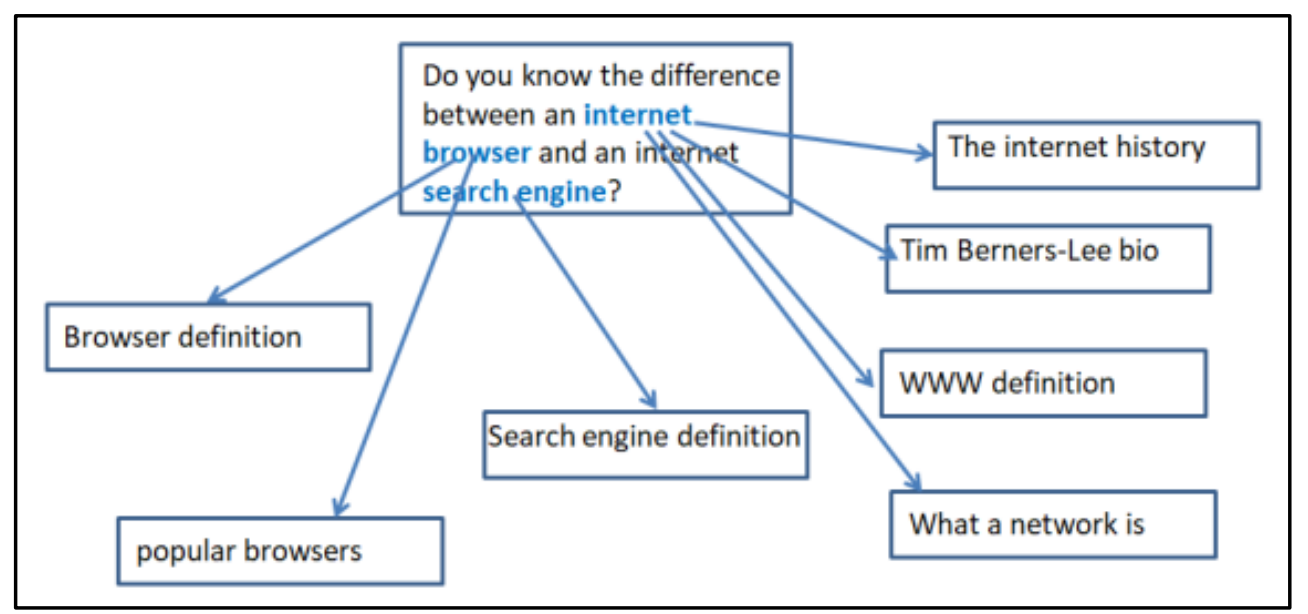

Fig. 3. Integrative materials associated to a question

The same integrative materials can be associated to various different learning units.

The second step consists in improving the integrative materials, analyzing learner behavior. Learners are regularly asked to evaluate their learning process (e.g. every two hours of connection). Their responses, as well as the length of time they have spent on learning objects, are presented in a dashboard visible to the teacher, who uses the information to improve the integrative materials.

Examples of questions are as follows:

- Did this learning object satisfy your expectations? (Not at all, Slightly, Fair, Very, Extremely)

- How do you evaluate the topicality of this learning object? (Very poor, Scant, Adequate, Good, Very good)

- How do you evaluate the learning object examples? (Very poor, Scant, Adequate, Good, Very good)

- How do you evaluate the learning object exercise? (Very poor, Scant, Adequate, Good, Very good)

\section{A Likert scale is used for the learner evaluation.}

Learners can also post comments and suggestions in forums and chat. Their posts are analyzed, and the results are presented in the teacher dashboard. The teacher uses all the information coming from learners to refine the learning units by improving the learning objects.

This second step can be iterated.

The solution has been implemented for the smart learning environment of the ASL project. The six project partners from five countries (Turkey, Latvia, Italy, Poland, and Greece) will use it to train lowly-qualified learners on basic and advanced notions related to digital technologies.

Each partner will organize two training courses. In the first, teachers will implement the first step of the solution, using the results obtained to then refine the second training course.

\section{FURTHER DEVELOPMENTS}

The next main development will be the integration of adaptive learning functions in remote learning activities. The possibility of developing a collaborative group activity aimed at creating integrative materials will be investigated. Small groups of learners could use the internet to research for pre-knowledge materials as well as other information able to facilitate the learning process and the achievement of the learning objectives.

Free brainstorming tools could be experimented and integrated into the smart learning environment [21], [22].

Moreover, agents to analyze the forum and chat activities should be implemented to identify the learners' preferences and learning difficulties.

The idea is to design and develop a dashboard to help a teacher improve the learning units and their remote learning activities.

For this purpose, learning analytics will be used to create and update a set of learner profiles based on the learners' behavior [23], [24]. A weight that expresses the learner's preference and difficulty will be associated with each learning content.

The next step foresees the possibility of using Bayesian inference to implement an algorithm to automatically refine personalized learning paths [25], [26], [27].

An algorithm will be developed to identify the best learner profile based on a preliminary test before starting the elearning course. The hypothesis is to use a Bayesian-based algorithm, since it should enable the association of a learner to a particular profile. If the learner's status corresponds to the likelihood of a particular profile, and there is other evidence, e.g. learner actions, supporting that probability, then the learner can be associated to a specific profile.

Indeed, the Bayes theorem describes the probability of an event, based on a prior knowledge of conditions that might be related to the event. It is expressed as: 


$$
P(A \mid B)=\frac{P(B \mid A) P(A)}{P(B)}
$$

where $P(A)$ and $P(B)$ are independent probabilities of event $A$ (learner profile) and $B$ (learner status) respectively, and $P(A / B)$ is the probability of observing $A$ (learner profile), given the event $B$ (learner status) has happened.

In SALM, we aim to infer the parameters $(\theta)$ of our model as:

$$
P(\theta / D)=[P(D / \theta) . P(\theta)] / P(D)
$$

where $P(\theta)$ is the prior belief; $P(D / \theta)$ is the likelihood of data $D$, given that $\theta$ is observed or true; and $P(D)$ is a normalizing constant.

\section{CONCLUSION}

For a long time, most of the popular digital platforms were generally conceived in terms of content distribution systems, with little thought given to the interests or immediate reactions of singular learners in the virtual classroom.

The COVID-19 outbreak forced the creation of more interactive learning environments and experimental solutions that facilitate personalized teaching-learning.

This paper has presented a solution aimed at combining automatic and mediated adaptive learning. It results from research carried out on digital transformative learning focusing on smart learning environments that can support easy, engaged, and productive learning.

At this time, a solution has been implemented based on structured learning units and a pre-determined but flexible teaching strategy. It will be adopted for the training activity of the EU ASL project.

\section{ACKNOWLEDGMENTS}

This paper has been supported by the board of Science of Latvia within the scope of the project "Implementation of Transformative Digital Learning in Doctoral Program of Pedagogical Science in Latvia” (DocTDLL) lzp-2018/20180 and by the ASL project co-funded by the Erasmus + Programme of the European Union (Adult self-learning: supporting learning autonomy in a technology-mediated environment, reference number 2019-1-TR01-KA204076875). The views expressed reflect those of the authors alone.
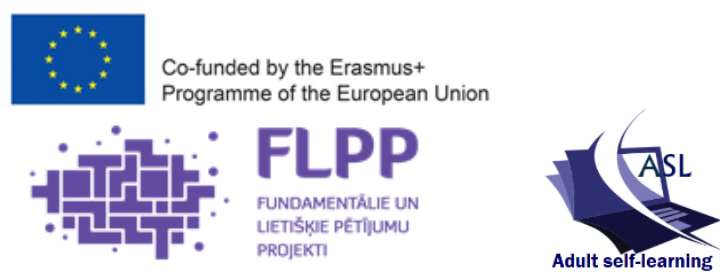

\section{REFERENCES}

[1] F. J. García-Peñalvo, A. Corell, R. Rivero-Ortega, M. J. RodríguezConde and N. Rodríguez-García, "Impact of the COVID-19 on Higher Education: An Experience-Based Approach", In Information Technology Trends for a Global and Interdisciplinary Research Community. IGI Global, pp. 1-18, 2021.

[2] G. Marzano and A. Zając, "Managing Education During The Coronavirus Emergency: The Case Of A Polish Higher Education Institution”, Education. Innovation. Diversity., 1(1), pp. 37-47, 2020.

[3] R. L. Quezada, C. Talbot and K. B. Quezada-Parker, "From Bricks and Mortar to Remote Teaching: A Teacher Education Program's Response to COVID-19”. Journal of Education for Teaching, 46(4), pp. 472-483, 2020.

[4] S. Senel and H. C. Senel, "Remote Assessment in Higher Education during COVID-19 Pandemic.” International Journal, 8(2), pp. 181-199, 2021.

[5] O. Zawacki-Richter, "The current state and impact of Covid-19 on digital higher education in Germany". Human Behavior and Emerging Technologies, 3(1), pp. 218-226, 2021.

[6] R. Oppermann and R. Rasher, “Adaptability and adaptivity in learning systems”. Knowledge transfer, 2, pp. 173-179, 1997.

[7] C. D. Dziuban, P. D. Moskal, J. Cassisi and A. Fawcett, "Adaptive Learning in Psychology: Wayfinding in the Digital Age”. Online Learning, 20(3), 74-96, 2016.

[8] F. Martin, Y. Chen, R. L. Moore and C. D. Westine, "Systematic review of adaptive learning research designs, context, strategies, and technologies from 2009 to 2018”. Educational Technology Research and Development, 68(4), pp. 1903-1929, 2020.

[9] D. Ifenthaler, D. K Mah and J. Y. K. Yau (Eds.), Utilizing learning analytics to support study success. Springer, 2019.

[10] R. Ferguson, "Learning analytics: drivers, developments and challenges”. International Journal of Technology Enhanced Learning, 4(5-6), pp. 304-317, 2012.

[11] R. Huang, J. Yang and Y. Hu, Y. "From digital to smart: The evolution and trends of learning environment”. Open Education Research, 1(1), pp. 75-84, 2012.

[12] S. Day and E. Erturk, E. "e-Learning objects in the cloud: SCORM compliance, creation and deployment options". Knowledge Management \& E-Learning, 9(4), pp. 449-467, 2017.

[13] K. Shutler, SCORM is dead - what are the alternatives to SCORM?, 2018, August 22. Available at: https://plume.co.uk/blog/scorm-isstagnant-heres-what-to-use-instead/

[14] H. M. Truong, "Integrating learning styles and adaptive e-learning system: Current developments, problems and opportunities”. Computers in human behavior, 55, 1185-1193, 2016.

[15] G. Marzano and V. Lubkina, V., “An adaptive learning model based on a machine learning approach”, International Conference on Mechatronics and Robotics, Dubai, February 26-27, 2020. Available https://www.researchgate.net/publication/341709563 An adaptiv e_learning_model_based_on_a_machine_learning_approach

[16] A. H. Nabizadeh, D. Gonçalves, S. Gama, J. Jorge and H. N. Rafsanjani, "Adaptive learning path recommender approach using auxiliary learning object”. Computers \& Education, 147, 103777, 2020.

[17] C. J. Hame and D. Ryan-Jones, "Designing instruction with learning objects". International Journal of Educational Technology, 3(1), pp. 111-124, 2002.

[18] D. A. Wiley, The instructional use of learning objects (Vol. 1). Bloomington, IN: Agency for instructional technology, 2002.

[19] P. Barker, P., "What is IEEE learning object metadata/IMS learning resource metadata”. CETIS Standards Briefing Series, JISC (Joint Information Systems Committee of the Universities' Funding Councils), $2005 . \quad$ Available at: http://www.dia.uniroma3.it/ sciarro/elearning/WhatIsLOMscreen.pdf

[20] S. H. Pitkanen and P. Silander, "Criteria for pedagogical reusability of learning objects enabling adaptation and individualised learning 
Environment. Technology. Resources. Rezekne, Latvia Proceedings of the $13^{\text {th }}$ International Scientific and Practical Conference. Volume 2, 93-99

processes". In IEEE International Conference on Advanced Learning Technologies, 2004. Proceedings, pp. 246-250, 2004 August.

[21] H. Al-Samarraie and S. Hurmuzan, "A review of brainstorming techniques in higher education”. Thinking Skills and Creativity, 27, pp. 78-91, 2018.

[22] Y. Maaravi, B. Heller, Y. Shoham, S. Mohar and B. Deutsch, "Ideation in the digital age: literature review and integrative model for electronic brainstorming”. Review of Managerial Science, pp. 1-34, 2020.

[23] F. Gjermeni and B. Percinkova, “Combining Intelligent Algorithms and E-Learning Styles to Create an Improved Intelligent System in Evaluating an E-Learning Student's Profile”. ANGLISTICUM. Journal of the Association-Institute for English Language and American Studies, 7(2), 11-21, 2018.
[24] H. Peng, S. Ma and J.M. Spector, "Personalized adaptive learning: an emerging pedagogical approach enabled by a smart learning environment”. Smart Learning Environments, 6(1), pp. 1-14, 2019.

[25] O. Akhrif, C. Benfares and N. Hmina, N., "Collaborative learning services in the smart university environment", In Proceedings of the 4th International Conference on Smart City Applications. Article no. 42, 2019, October.

[26] J. W. Kim and F. E. Ritter, F.E. "Consideration of a Bayesian Hierarchical Model for Assessment and Adaptive Instructions”. In International Conference on Human-Computer Interaction, pp. 521-531, 2019 July.

[27] N. Sclater, N., Learning analytics explained. Taylor \& Francis, 2017. 